\title{
Utilitas
}

http://journals.cambridge.org/UTI

Additional services for Utilitas:

Email alerts: Click here

Subscriptions: Click here

Commercial reprints: Click here

Terms of use : $\underline{\text { Click here }}$

\section{Mill, Intuitions and Normativity}

\section{CHRISTOPHER MACLEOD}

Utilitas / Volume 25 / Issue 01 / March 2013, pp 46 - 65

DOI: 10.1017/S095382081200026X, Published online: 06 March 2013

Link to this article: http://journals.cambridge.org/abstract_S095382081200026X

How to cite this article:

CHRISTOPHER MACLEOD (2013). Mill, Intuitions and Normativity. Utilitas, 25, pp 46-65 doi:10.1017/S095382081200026X

Request Permissions : $\underline{\text { Click here }}$ 


\title{
Mill, Intuitions and Normativity
}

\author{
CHRISTOPHER MACLEOD \\ University of Lancaster
}

\begin{abstract}
It is the purpose of this article to offer an account of Mill's metaethics. Expanding upon clues given recently by Dale Miller, and previously by John Skorupski, I suggest that when it comes to the foundations of his philosophy, Mill might share more with the intuitionists than we are accustomed to think. Common wisdom holds that Mill had no time for the normativity of intuitions. I wish to dispute, or at least temper, this dogma, by claiming that Mill's attitude towards intuitions is far more complex and ambivalent than is generally thought. I argue that, according to Mill, our belief in the reliability of inductive moves and apparent memories, as well as the desirability of pleasure, is vindicated by something akin to intuition. Although his endorsement of the normativity of these intuitions might seem to be in tension with the arguments he offers against the 'intuitionist school', this tension is only apparent.
\end{abstract}

\section{INTRODUCTION}

We still possess a surprisingly limited understanding of the metaethical foundations of John Stuart Mill's utilitarianism. Alan Ryan's interpretation in 1970 led to a general consensus that Mill is best read as a non-cognitivist about moral statements. ${ }^{1}$ Discussion of Mill's metaethics has moved little in the proceeding forty years, while understanding of the metaethical landscape itself has changed much; a return to the subject in light of this shifting understanding is therefore timely. In this spirit, it has recently been argued that the noncognitivist reading of Mill is at best suspicious: the textual evidence for Mill's non-cognitivism is far from conclusive and a belief in the truthinaptitude of norms is incompatible with Mill's clear commitment to the possibility of providing evidence for those norms. ${ }^{2}$

It is therefore worth enquiring within what confines Mill can hold that moral norms are beliefs that aim at truth, rather than truth-inapt expressive or prescriptive speech acts. The most pertinent questions are what the metaphysics and epistemology of these normative truths would amount to (what normative facts would under a Millian picture be, and how we could come to have cognitive contact with them). It is the purpose of this article to tackle these questions, by expanding on clues given recently by Dale Miller, and previously by John Skorupski, to the effect that, when it comes to the foundations of his philosophy,

1 See A. Ryan, The Philosophy of John Stuart Mill, 2nd edn. (Basingstoke, 1987), p. 189. The first edition of this work was published in 1970.

${ }^{2}$ C. Macleod, 'Was Mill a Non-Cognitivist?', Southern Journal of Philosophy (forthcoming). 
Mill might share more with the intuitionists than we are accustomed to think. ${ }^{3}$ The investigation, then, centres on the question of whether, for Mill, intuitions carry normative warrant: whether, in itself, the fact that a belief is intuitional provides reason to think that belief a warranted one. Common wisdom holds that Mill had no time for the normativity of intuitions. ${ }^{4}$ I wish to dispute, or at least temper, this dogma, by claiming that Mill's attitude towards intuitions is far more complex and ambivalent than has previously been thought.

This investigation of Mill's metaethics proceeds by considering his thought on the norms of practical and theoretical reason more broadly. Though the claim cannot be separately defended - support for it will nevertheless emerge in section III - it is a working supposition of this article that Mill's account of the foundations of practical reason (what grounds reason to act) runs broadly in parallel with his account of foundations of theoretical reason (what grounds reason to believe). I therefore draw freely on Mill's account of the grounds of theoretical reason in discussing the grounds of his ethics. ${ }^{5}$

I begin in section II by setting out Mill's stated arguments against intuitionism. The intuitionists claim that intuitions carry force in determining what we should believe and how we should act. There is no doubt that Mill means to deny that the intuitions generally cited by his opponents carry force: he makes his views on this issue explicit. Mill offers two sorts of arguments for the dismissal of those (purported) intuitions, however, which are quite different in orientation. Additionally, he acknowledges that a conviction regarding the reasonableness of believing apparent memories is intuitive. Mill's view on the normative standing of intuitions, it emerges, is far from simple.

I continue in section III by arguing that Mill himself appeals to something close to intuition when attempting to justify the reasonableness of believing in the results of inductive inference, and in thinking pleasure desirable. In section IV, I offer a reading of Mill that dissolves these tensions, which answers the question of Mill's epistemology and metaphysics of normativity. For Mill, norms are not

3 See D. E. Miller, J. S. Mill (Cambridge, 2010), pp. 17-20, 44; D. E. Miller, 'John Stuart Mill's Moral, Social, and Political Philosophy', Oxford Handbook of British Philosophy in the Nineteenth Century, ed. W. Mander (Oxford, forthcoming); J. Skorupski, John Stuart Mill (London, 1989), pp. 194, 228-9, 286; and J. Skorupski, 'Introduction: The Fortunes of Liberal Naturalism', The Cambridge Companion to Mill, ed. J. Skorupski (Cambridge, 1998), pp. 1-34, at 6-8.

${ }^{4}$ W. Stafford, John Stuart Mill (London, 1998), p. 57, for instance, is not untypical: 'Mill believes that intuitivism is at once irrational, and a bastion of conservatism in moral and politics. It makes opinions their own proof, and feelings their own justification.'

5 Taking Mill's theory of practical and theoretical reason to be parallel does not involve any special innovation. See Ryan, The Philosophy of John Stuart Mill, p. 187. 
substantive facts that make up part of the external world; we can know them without causal interaction because they are truth-apt, but not by virtue of correspondence to the way the world is.

\section{MILL'S ARGUMENT AGAINST INTUITIONISM}

Mill's commitments within metaphysics and epistemology are made by way of the division between what is variously called the a priori, deductive, intuitionist, metaphysical, Platonic or German school on the one hand, and the a posteriori, inductive, psychological, empirical, Aristotelian or British school of philosophy on the other. ${ }^{6}$ On this birdseye-view division of philosophy, Mill places himself within the latter camp. Of the intuitionist school, he can regularly be found making comments such as the following:

I consider that school of philosophy as the greatest speculative hindrance to the regeneration so urgently required, of man and society; which can never be effected under the influence of a philosophy which makes opinions their own proof, and feelings their own justification. ${ }^{7}$

Mill held that the 'notion that truths external to the human mind may be known by intuition' was in his time 'the great intellectual support for false doctrines'. ${ }^{8}$ His philosophic loyalties lie with the a posteriori school. He is committed to a programme of uncompromising empiricism and, as such, he wishes to establish all substantive knowledge of the world as a result of observation of the world.

Appeal to intuition to justify belief is suspect on the grounds that it does not involve direct empirical observation of the world. Mill's view is that if there are any innate beliefs - this is a question answerable only by empirical study of the mind - their status must themselves be subject to natural enquiry. We think of our ordinary, non-intuitive, beliefs as naturally explicable, and as no a priori guarantor of truth. Similarly, Mill thinks, the existence of any intuitive beliefs would be naturally explicable, and would carry no a priori indication of truth. And, as a matter of empirical fact, he suggests, those beliefs that are commonly taken to be innate are in fact not so. They have been formed by experience, and have been mistaken for innate ideas because of their apparent prevalence or irresistibility.

6 See, for instances of the contrast, Mill, Autobiography, ch. 7, Collected Works [hereafter $C W$ ] I: 233, 269; Mill, System, VI.iv.4, CW VIII: 859; Mill, Coleridge, $C W$ X: 120, 125; Mill, Whewell on Moral Philosophy, CW X: 193; Mill, Auguste Comte and Positivism, ch. 1, CW X: 307-8; Mill, Grote's Aristotle, CW XI: 487. Quotes from Mill will be taken from The Collected Works of John Stuart Mill, ed. J. M. Robson (Toronto, 1963).

7 Mill, Letter to Theodor Gomperz, 19 August 1854 (183), CW XIV: 239.

8 Mill, Autobiography, ch. 7, CW I: 233. 
The reduced portfolio claim

There are two claims that are often entangled and polemically mixed by Mill, which should be carefully distinguished. The first, the reduced portfolio claim, is that the intentional states that are taken to be intuitional are in fact not so, but are instead the result of a process of mental formation. Beliefs that are said to belong to the set of intuitions have been mistakenly placed there, belonging in reality to the set of acquired beliefs.

In chapter VI of the Examination, Mill notes that many think that a belief in the endlessness of space is intuitional. He offers an alternative account of that belief, as acquired by a particularly strong process of the association. Under investigation, the belief can be explained naturally, and, as such, 'we have no ground for belief that it is so from the original structure of our minds. ${ }^{9}$

That we are unable to conceive an end to space I fully acknowledge... . We are disabled from forming this conception, by known psychological laws. We have never perceived any object, or any portion of space, which had not other space beyond it. And we have been perceiving objects and portion of space from the moment of birth. How then could the idea of an object, or of a portion of space, escape becoming inseparably associated with the idea of additional space beyond? Every instant of our lives helps to rivet this association, and we never have had a single experience tending to disjoin it. ${ }^{10}$

The apparent intuition that space is infinite is, Mill argues, nothing more than an acquired belief, held particularly strongly because of the conditions under which it was acquired. There may be reasons to trust the belief, and there may be reasons to doubt it, but it should not be thought privileged, and ought to be evaluated as are other acquired beliefs.

Mill gives a similar associationist account of how we come to believe in the existence of the external world in chapter XI of the Examination. Here his project is to 'state the cases of those who hold that the belief in an external world is not intuitive, but an acquired product'. ${ }^{11}$ In short, Mill's narrative, which accounts for a belief in the external world and undercuts its status as an intuitive belief, involves initial sensory impressions being presented to the mind and generating expectations and anticipations of future impressions. '[A]fter having had actual sensations, we are capable of forming the conception of Possible sensations'. ${ }^{12}$ These possibilities-for-sensation are more permanent and become more important to us than fleeting sensations, and it is

9 Mill, Examination, ch. 6, CW IX: 82.

10 Mill, Examination, ch. 6, CW IX: 82.

11 Mill, Examination, ch. 11, CW IX: 177.

12 Mill, Examination, ch. 11, CW IX: 177. 
this character that distinguishes them from the former. We apply a new name ('matter') to the possibilities, and even though this is merely sensation 'regarded in a different aspect', ${ }^{13}$ 'the different name comes to be considered as the name of a different thing. ${ }^{14}$ The upshot: matter is an acquired, and not intuitive, belief.

Even where Mill is cautious about the reduced portfolio claim, it is the strategy he is tempted to follow.

I ... admit that if there are any inherent necessities of thought, [the principles of contradiction, excluded middle, and identity] are such. I express myself in this qualified manner, because whoever is aware how artificial, modifiable, the creatures of circumstances, and alterable by circumstances, most of the supposed necessities of thought are (though real necessities to a given person at a given time), will hesitate to affirm of any such necessities that they are an original part of our mental constitution. Whether the three so-called Fundamental Laws are laws of our thoughts by the native structure of the mind, or merely because we perceive them to be universally true of observed phaenomena, I will not positively decide ... They may or may not be capable of alteration by experience[.] ${ }^{15}$

We should note that the reduced portfolio claim, in itself, does not question the force of intuition - the move from 'intuitional belief' to 'warranted belief' is not challenged. The reduced portfolio claim is simply that intentional states that on first sight appeared to be intuitions are in fact not so, and should be evaluated as are other acquired beliefs. The very fact that this strategy is deployed against the intuitional school with such fervour and so often by Mill might be thought to carry the implication that Mill would accept the legitimacy of appeals to intuition in principle if any could be made, merely denying that there have been genuine intuitions identified. But such an interpretation will not sit well with the second line of attack pursued by Mill.

\section{The intuitional fallacy}

The charge of the intuitional fallacy centres itself directly on the standing of intuitions - whether the status of a belief as intuitional could provide a priori support for the content of that belief. Here, it is granted that the objects under consideration are genuine intuitions. The argument is that these beliefs, even if they are intuitive, cannot act as direct evidence about how the world is. To commit the intuitional fallacy is to believe that the way the mind is composed can, on its own, act as a guide to how the rest of the world is.

13 Mill, Examination, ch. 11, CW IX: 180.

14 Mill, Examination, ch. 11, CW IX: 180.

15 Mill, Examination, ch. 21, CW IX: 380. 
Consider, for example, a belief given by intuition that God exists. (Mill, as ever, wavers between the denial that this is an intuition and that even if it were an intuition it would be untrue, though this should not concern us here. ${ }^{16}$ ) The question is this: what is it about the fact that my mind is so constituted as to believe this particular proposition that means that I should believe it? If, as Mill believes, the mind is a natural object, there will be a natural explanation for the intuition: some causal account as to why the mind happens to be constituted so as to find God's existence plausible. What there is not, in any obvious way, is direct evidence of truth. Our tendency to find certain facts intuitively obvious or inconceivable 'is in truth very much an affair of accident, and depends on the past history and habits of our own minds' ${ }^{17}$

Of course, there could in principle be good empirical evidence that possessing an intuitive belief is evidence of the truth of that belief. One might tell, for instance, an evolutionary story about intuitions that vindicate them either individually or en masse. Under this account, though, whether the intuition can be vindicated is itself a matter for empirical investigation, and cannot be taken for granted or inferred from facts about the mind in isolation. The argument that the content of the intuition is true, that is to say, will itself be an empirical one: it will not be from a fact about the mind on its own that the intuition is validated, but from that fact about the mind in combination with an empirical backstory. It remains a fallacy to think that one can infer facts about how the world is directly from the content of one's own mind.

Mill's most explicit statement against the intuitional fallacy comes in the sixth chapter of the Examination. Mill here discusses the proposal that we have intuitive knowledge of certain facts, on the basis that we cannot conceive of them being false.

[E]ven assuming ... that some incapacities of conceiving are inherent in the mind, and inseparable from it; this would not entitle us to infer, that what we are incapable of conceiving cannot exist. Such an inference would only be warrantable, if we could know a priori that we must have been created capable of conceiving whatever is capable of existing: that the universe of thought and that of reality, the Microcosm and the Macrocosm (as they once were called) must have been framed in complete correspondence with one another. ${ }^{18}$

Mill goes on to suggest that 'an assumption more destitute of evidence could scarcely be made' and states simply that '[w] hat is inconceivable, then, cannot therefore be inferred to be false'. ${ }^{19}$

16 See Mill, Theism, CW X: 442; cf. Mill, Examination, ch. 4, CW IX: 36.

17 Mill, System, II.v.6, $C W$ VII: 238.

18 Mill, Examination, ch. 6, CW IX: 68.

19 Mill, Examination, ch. 6, CW IX: 68. 
Mill also explicitly rejects the move from innate to true during a discussion in the Logic of Spencer's claim that intuitions are reliable on the basis that they are truths acquired a posteriori by previous generations and inherited in the manner of Lamarckian acquired characteristics. '[A] conviction might be really innate, i.e. prior to individual experience, and yet not be true, since the inherited tendency to accept it may have been originally the result of other causes than its truth. ${ }^{20}$ Mill here accepts what must be the naturalistic position on intuitions: that they are, as are all mental states, causally explicable, and therefore can carry no a priori implication to other truths about the world. A conviction could be innate merely as a quirk of our collective psychology - we have no a priori guarantee of truth preservation. Matters of fact cannot relate to each other logically, and a valid inference cannot be made from a person's state of mind to an external fact, except with a relevant causal story about how the relevant external fact has caused the belief.

Mill pursues the line of attack focusing on the intuitional fallacy far less vigorously than he does the reduced portfolio claim. It is perhaps his less preferred tactic because it is less rhetorically striking than the reduced portfolio claim, or perhaps because he has independent motivation to demonstrate the power and breadth of associationism in explaining away apparent intuitions. It is clear, however, that it is this sort of uncompromising argument that Mill requires if he is to maintain that it is for philosophic reasons, rather than on the grounds of our particular psychological makeup, that there are 'no truths cognizable by the mind's inward light, and grounded on intuitive evidence'. ${ }^{21}$

\section{The memory intuition}

W. G. Ward, in his 1860 On Nature and Grace, accuses Mill of appealing to an intuition to justify the reasonableness of believing one's apparent memories. The argument is as follows: Mill seeks to ground his beliefs on experience, but in order to do so, he must assume his memories of past experiences are accurate. A belief in the accuracy of past apparent memories cannot be justified by appeal to further experience, because the recollection of that further experience would itself need to be assumed reliable.

You make use of your own past experience ... as part of the foundation on which you build. How can you even guess what your past experience has been? By trusting memory. But how do you prove that those various intuitive judgments, which we call acts of memory, can rightly be trusted? So far from this being provable by past experience, it must be in each case assumed and

20 Mill, System, II.vii.4, CW VII: 276.

21 Mill, Coleridge, CW X: 125. 
taken for granted, before you can have any cognizance whatever of your past experience. $^{22}$

The belief that apparent memories should in general be trusted, Ward claims, is therefore an intuitive one, not amenable to prior demonstration. Mill's reaction is hard to reconcile with a view of him as uniformly hostile to intuitionism. In early editions of the Examination, Mill acknowledges that the use of memory relies on this 'ultimate' belief and that "no reason can be given for it which does not presuppose the belief, and assume it to be well grounded' ${ }^{23}$ There is a clear implication, when this remark is placed alongside Mill's description of Ward as 'one of the most effective champions of the Intiutive school', ${ }^{24}$ that a belief in the reliability of memory has been acknowledged as intuitive. In later editions, when challenged to explain 'where the distinction lies between acts of memory and other alleged intuitions', Mill writes that

[t]he distinction is, that as all the explanations of mental phenomena presuppose Memory, Memory itself cannot admit of being explained. Whenever this is shown to be true of any other part of our knowledge, I shall admit that part to be intuitive. ${ }^{25}$

The point has at this stage been conceded: we have an intuitive belief that apparent memories are generally trustworthy. ${ }^{26}$ And, with this, Mill accepts that such genuinely inexplicable intuitions are, as intuitions, warranted. Moreover, at the end of the section in which Ward is discussed, Mill hints that he may be willing to acknowledge other intuitions that can be argued for in the manner of Ward: 'I have avowedly left the question undecided whether our perception of ourselves - of our own personality - is not a case of the same kind. ${ }^{27}$

It should be clear by this point that Mill's relationship with intuitionism is, in fact, far more complex and ambivalent than we are

22 W. G. Ward, On Nature and Grace: A Theological Treatise (London, 1860), p. 26.

23 Mill, Examination, ch. 10, CW IX: 164n.

24 Mill, Examination, ch. 10, CW IX: 165n. More precisely, Mill claims that Ward would be considered an effective champion of the school, were his work not addressed specifically to Catholics.

25 Mill, Examination, ch. 10, CW IX: 165n.

26 We should distinguish between the abstract intuition, conceptually prior to presentation of apparent memories that apparent memories are generally trustworthy and a concrete intuition that this apparent memory is trustworthy. It is not clear whether Ward and Mill are referring to the concrete or the abstract intuition, or indeed if they even adequately make this distinction. The abstract intuition can be inductively established from instances of the concrete, and it seems to me unnecessary to suppose that anything beyond the concrete intuition is vindicated as such, and so I will not consider this issue further in this article. A fuller account of Mill's views on intuition would need to take a position on this issue, however, for the same distinction can be made with respect to intuitions regarding induction and pleasure.

27 Mill, Examination, ch. 10, CW IX: 166n. 
accustomed to think. It is not philosophically problematic to deploy the reduced portfolio argument while at the same time holding that an appeal to intuition would in any case involve a fallacy. It nevertheless may suggest that Mill's thought on intuition is many-sided. A claim that it is fallacious to appeal to intuition to justify one's beliefs, in combination with the appeal to intuition in order to justify a belief in the trustworthiness of memory, however, does seem problematic. We will revisit this tension - which I will suggest is only apparent in section III. Before doing so, however, we should investigate the existence of other potential Millian intuitions.

\section{MORE INTUITION: INDUCTION AND PLEASURE}

I have not yet sought to define what an 'intuition' is, or how we should identify one. Mill never offers a full answer to this question, though it is clear in the discussion of memory that at least one criterion must be that an intuition 'cannot admit of being explained'. ${ }^{28}$ Of course, the intuition will be explicable in some sense: there will be some causal account, some story about atoms and neurology, which answers the question of why the intuition exists. The condition seems to be most naturally construed as the claim that it cannot be explained in psychological terms why we have this belief. Call this condition 'primitiveness'.

Clearly, this is not the sole necessary and sufficient property of an intuition. Mill perhaps passes over other conditions because they are well enough recognized as features of intuitive belief to be taken for granted, but it will do us no harm to make these features explicit. There has been much discussion of intuition in the recent literature on philosophical methodology: with a focus on the use of intuitions as evidence and the apparent disparity of intuitions between different cultural groups, there has also come an increasingly nuanced understanding of how we ought to identify intuitions. ${ }^{29}$ George Bealer provides a phenomenological condition:

28 Mill, Examination, ch. 10, CW IX: 165n.

29 It would clearly be naïve to suppose that philosophical usage of the term 'intuition' has remained stable between the nineteenth century and our time. Most obviously, the dominance of philosophy of language in the twentieth century has connected 'intuition' with the manifestation of conceptual or linguistic competence. (We possess an intuition about whether some Gettier case is knowledge in virtue of basic competence with the term 'knowledge' that is, in some sense, being made explicit by these judgments in fringe cases.) Nevertheless, I assume that enough connects intuitions new and old - that they are at their base not entirely different concepts which merely happen to be expressed by the same word - to draw on the recent debate without being overly anachronistic. 
[f]or you to have an intuition that A is just for it to seem to you that A. Here 'seems' is understood, not as a cautionary or 'hedging' term, but in its use as a term for a genuine kind of conscious episode. ${ }^{30}$

I might find myself with a belief that is primitive in the sense above, which I nevertheless do not find attractive upon inspection. If it transpired that I was constituted so as to have the unreflective primitive belief that apparent memories are generally trustworthy, but nevertheless felt no inclination towards believing this on reflection, we would not classify it as an intuition. Intuitive beliefs must 'seem', and the seeming must be direct: not so on the basis of some further belief. ${ }^{31}$ While 'this kind of seeming is intellectual, not sensory or introspective', it presents itself with similar force. ${ }^{32}$

Yet, in placing the emphasis on conscious episodes, the category of intuition is limited beyond the normal range of the term. It is not merely the conscious episodes themselves that we characterize as intuitions, but also the disposition to be presented with such seeming beliefs. I do not cease to have an intuition when I cease to attend to it mentally, and it is perfectly reasonable to talk in terms of 'consulting my intuitions' about a matter before I have previously had opportunity consciously to experience in what direction a seeming might lead me to believe. ${ }^{33}$

Much more could be said about 'intuition' - the category is difficult and elusive. ${ }^{34}$ We have, nevertheless, features that might be said to mark out the class. Intuitions are primitive dispositions to form beliefs that involve direct 'seeming'. The memory intuition satisfies each of these conditions. It is primitive, not psychologically explicable, but rather presumed in psychological explanation. We are disposed to believe that apparent memories are trustworthy on the basis of our psychological makeup, and they seem to us true on inspection.

30 G. Bealer, 'A Theory of the A Priori', Pacific Philosophical Quarterly 81 (2000), pp. $1-30$, at 3 .

31 J. W. Weinberg, 'How to Challenge Intuitions Empirically Without Risking Skepticism', Midwest Studies in Philosophy 31 (2007), pp. 318-43, at 321.

32 Bealer, 'A Theory of the A Priori', p. 3.

33 Bealer, 'A Theory of the A Priori', p. 3.

34 It is perhaps worth highlighting one departure from orthodoxy, however. It is often said that intuition connects us with necessary truths. If we gain knowledge of the trustworthiness of memory by intuition, however, it is not knowledge that memory is necessarily trustworthy. There seems, however, doubt about this condition. So, for instance, Bealer notes: 'I am unsure how exactly to analyze what is meant by saying that a rational intuition presents itself as necessary' (G. Bealer, 'Intuition and the Autonomy of Philosophy', Rethinking Intuition: The Psychology of Intuition and Its Role in Philosophical Inquiry, ed. M. R. DePaul and W. Ramsey (Oxford, 1998), pp. 20139, at 207), and Sosa writes: 'One might quite properly wonder why we should restrict ourselves to modal propositions. And there is no very deep reason. It's just that this seems the proper domain for philosophical uses of intuition' (E. Sosa, 'Experimental Philosophy and Philosophical Intuition', Philosophical Studies 132 (2007), p. 101). 


\section{Induction}

Mill's approach to the normative is deeply anthropological. In order to uncover good methods of reasoning and desirable ends of action, he believes, we must begin with observation of the practice of agents. In this sense, Mill's work is not addressed to the philosophically motivated sceptic, who doubts that there are or can be reasons at all. It is a supposition of Mill's work that the goal of philosophy is to reform and sharpen pre-philosophic practices of reasoning. Examining how reasoning does in fact take place is Mill's route to discovering how we ought to reason better. 'The laws of our rational faculty, like those of every other natural agency, are only learnt by seeing the agent at work. ${ }^{35}$

Mill's claim is that close examination of the reasoner reveals one fundamental type of theoretical reasoning: enumerative induction. The goal of the System is to vindicate this process of reasoning. As with the principle of utility - Mill makes the parallel explicit - this can only ever be the vindication of an already existent norm, and never a proof. ${ }^{36} \mathrm{His}$ vindication has two steps. The first step towards justifying induction is the observation of our success as inductive reasoners. Inductive reasoning justifies itself throughout history: past inductions have been successful, and induction is in this sense inductively self-supporting, warranting future inductions. Consulting the history of our successful acquisition of knowledge - as a matter of biographical fact, Mill cites Whewell's History of Inductive Science and Comte's Cours de Positive Philosophie as his guides ${ }^{37}$ - we find that the sole substantive principle of theoretical reason employed with success is enumerative induction, and that this lends credibility to inductive moves. Induction inductively validates itself.

But, as Mill notes, this holistic vindication will only be persuasive once there are successful inductions to which we can appeal. This justification of induction provides no way to get induction 'off the ground': no story about why reasoners initially reason in this way before observing its historical success. What is needed is not an abstract proof of the validity of those inductions, but merely a story as to why they occur and are prima facie warranted. As Mill himself acknowledges, 'it is impossible to frame any scientific method of induction, or test

35 Mill, System, VI.i.1, CW VIII: 833.

36 'To be incapable of proof by reasoning is common to all first principles; to the first premises of our knowledge, as well as to those of our conduct' (Mill, Utilitarianism, ch. 4, $C W$ X: 234; my emphasis).

37 Mill, Autobiography, ch. 6, CW I: 215-17. 
of the correctness of inductions, unless on the hypothesis that some inductions deserving of reliance have been already made'. ${ }^{38}$

Inductions deserving of reliance are generated prior to the holistic vindication of induction, Mill thinks, by the natural psychological tendency to expect previous experience to generalize.

Many of the uniformities existing among phenomena are so constant, and so open to observation, as to force themselves upon involuntary recognition. Some facts are so perpetually and familiarly accompanied by certain others, that mankind learnt, as children learn, to expect the one where they found the other, long before they know how to put their expectation into words by asserting, in a proposition, the existence of a connexion between the phenomena. ${ }^{39}$

In the presence of many instances of Xs with Ys, we naturally form the belief that future Xs will come with Ys. Mill repeatedly describes the tendency as spontaneous: we 'spontaneously adopt' enumerative induction and generate resultant expectations about how the world is. It is a method of reasoning that is 'primitively pursued by the human understanding while undirected by science'. And though 'ulterior revision of these spontaneous generalizations' remains possible in light of the 'stricter and surer' findings, Mill is clear that the spontaneous generalizations provide us with genuine knowledge and warranted beliefs. $^{40}$

Induction, then, holds a similar status to memory. The characterization of inductive reasoning as spontaneous indicates that the tendency to form beliefs by acts of induction is primitive, in the sense of not admitting of further explanation. Mill is clear that induction cannot itself be justified by some further principle of reasoning, and that even where we appear to be using other methods, such as inference to the best explanation, induction lies beneath the tendency to anticipate that $\mathrm{X}$ will be followed by $\mathrm{Y}$ when they have previously been conjoined together is itself presupposed by any explanation of how we form rational beliefs. ${ }^{41}$ And we are not indifferent to our tendency to believe in the norm of induction: it seems to us true.

Mill's anthropological study of theoretical reasoning reveals that we are primitively disposed to believe in inductive moves on the grounds of a seeming that is not based on inference from any further facts, but is direct. As Skorupski has put it, '[w]e find ourselves in spontaneous agreement in reasoning that way, and equally, in holding that way of

38 Mill, System, III.iv.2, CW VII: 319.

39 Mill, System, III.iv.2, CW VII: 318.

40 Mill, System, III.iv.2, CW VII: 318.

41 See Mill System, III.xiv.4-7, CW VII: 490-508. 
reasoning to be sound. ${ }^{42}$ On the grounds Mill himself isolates, that is to say, we have an intuitive belief that inductive moves are generally trustworthy.

\section{Pleasure}

Mill's fundamental principle of theoretical reason is enumerative induction, and I have suggested that this is vindicated at the most fundamental level by something akin to an intuition about the trustworthiness of inductive moves. The practical parallel of induction for Mill is, of course, pleasure. As induction grounds theoretical reason, for Mill, pleasure grounds practical reason. It was noted above that Mill's method for finding the norms of theoretical reason was anthropological, starting from a consideration of the way in which reasoners operate. So too for practical reason: examining how practical reasoning does in fact take place is Mill's route to discovering how it ought to be done.

Examination of the actual process of practical reasoning reveals that there is only one end of action: pleasure. It is demonstrated in Utilitarianism that human beings act to attain this goal, and in that even where other desiderata seem appealing - justice, money, virtue these are only so in virtue of their contribution to pleasures. Mill's claim is that we are, as a matter of anthropology, creatures that seek pleasure, and it is recognition of this fact that is the first step in an investigation of how we ought to act.

The only proof capable of being given that an object is visible, is that people actually see it. The only proof that a sound is audible is that people hear it: and so of the other sources of our experience. In like manner, I apprehend, the sole evidence it is possible to produce that anything is desirable, is that people do actually desire it. ${ }^{43}$

Mill invites the consideration of pleasurable sensations - 'practised self-consciousness and self-observation' - and claims that we will find ourselves obliged to admit that these sensations seem desirable to us. 'Human nature is so constituted as to desire nothing which is not either a part of happiness or a means to happiness. ${ }^{24}$ As our tendency to spontaneously adopt inductive reasoning provides prima facie grounds for trusting it as a theoretical practice, so our spontaneous adoption of pleasure provides prima facie validation for this practical end. '[T]he

42 Skorupski, John Stuart Mill, p. 8.

43 Mill, Utilitarianism, ch. 4, CW X: 234.

44 Mill, Utilitarianism, ch. 4, CW X: 237. 
sole evidence it is possible to produce that anything is desirable, is that people do actually desire it. ${ }^{95}$

This, of course, is combined with the observation that pleasure is primitively desirable - that its desirability cannot be further explained. 'If the end which the utilitarian doctrine proposes to itself were not, in theory and in practice, acknowledged to be an end, nothing could ever convince any person that it was so. ${ }^{46}$ Mill does not think an explanation of why pleasure is desired as an end can be given: throughout Utilitarianism, he uses the principle to explain the emergence of other desires, but he clearly does not believe that there is a further account for why pleasure itself is desired: in his edition of his father's Analysis, he calls that fact 'ultimate'. ${ }^{47}$ In the System, he terms it a first principle, and draws the parallel with induction. 'There are not only first principles of Knowledge, but first principles of Conduct. ${ }^{48}$

There are, of course, differences between the theoretical and practical cases. I suggested above that we understand an intuition as a primitive disposition to believe on the basis of seeming. We have an intuition that inductive moves and apparent memories are trustworthy, and their status as genuinely intuitive vindicates this norm. At the basis of a practical case, however, there is not a primitive belief, but a primitive desire; not seeming, but appealing. We could, I think, abstract the definition of 'intuition' to make the practical case fit more easily: define intuition as pertaining to attracting intentional states rather than seeming beliefs. This would perhaps be insistence on slightly unnatural terminology. Whether we choose to call the desire for pleasure an intuition or not, however, the structural parallel to the theoretical case stands. We are drawn to pleasure, which we find appealing, on the basis of primitive desire that does not admit of further explanation. As the norm of inductive generalization is validated by psychological evidence, so the norm of pleasure is validated.

Mill's anthropological study of practical reasoning reveals that we are primitively disposed to desire pleasure on the grounds of appeal that is not based on the prospect of it eliciting further desiderata, but is direct.

45 Mill, Utilitarianism, ch. 4, CW X: 234. Note his claim that this is the only evidence: Mill offers no equivalent of the holistic justification of induction. As we shall see below, it remains possible that there could be evidence against this desirability of pleasure presented. What such evidence might be, however, Mill gives no indication, and this remains one of the most challenging aspects of his theory.

46 Mill, Utilitarianism, ch. 4, CW X: 234.

47 Mill, Editorial Comments on the Analysis, CW XXXI: 251. We should note, however, that he does not think this merely a truth by definition. Desire and pleasure are 'two things [that] are inseparable; not that they are, or that they can ever be thought of, as identical; as one and the same thing'. See also Mill, Utilitarianism, ch. 4, CW X: 237-8.

48 Mill, System, VI.xii.7, CW VIII: 951. See also Mill, Utilitarianism, ch. 4 CW X: 234, cited in $\mathrm{n} .36$ above. 
Miller is right, then, in noting that for Mill 'our innate disposition to desire pleasure justifies us in claiming to know intuitively that it is desirable. ${ }^{49}$

\section{RESOLVING THE TENSIONS}

It has been shown, then, that Mill's relationship to intuitionism is actually more complex and ambivalent than might be supposed. The difficulty of this relationship should not, in fact, surprise us. ${ }^{50} \mathrm{We}$ should keep in mind the high estimation in which certain intuitionist thinkers - particularly Coleridge, Carlyle, F. D. Maurice and John Sterling - were held by Mill. When Mill characterizes Bentham and Coleridge as the key representatives of the inductive and intuitionist schools of philosophy, he is clear that both have something to offer philosophy. It is telling that he claims that "whoever could master the premises and combine the methods of both, would possess the entire English philosophy of their age'. ${ }^{51}$ Often, when considering influence from outside the Benthamite tradition on Mill, discussions are confined to practical policies, and the claim is made that Mill wished to import conservative and romantic ideas into a more sensible framework. This is no doubt true in as far as it goes, but it is only part of the truth. Mill is explicit: it is also the theoretical aspects - 'the premises' and 'the methods' - of both schools that need to be integrated. The vehemence with which Mill can often be found to be attacking 'the intuitional' philosophy can therefore be misleading. In calmer moments, Mill can be found claiming that ' $[\mathrm{n}] \mathrm{o}$ one whose studies have not extended to both, can be considered in any way competent to deal with the great questions of philosophy in their present state. ${ }^{52}$

Nevertheless, the case should not be overstated. If they conflict, we should certainly not assume that Mill's appeal to our primitive and spontaneous dispositions in the case of vindicating foundational principles of memory, inductive reasoning and pleasure silences the numerous statements he makes against intuitionism. We must, therefore, identify if there is a real tension in Mill's thought, and if not,

49 Miller, J. S. Mill, p. 44 (my emphasis). Of course, this makes up only one part of a larger argument that is designed to prove that actions are right in proportion as they tend to promote aggregate pleasure.

50 Not least because Mill often praises those with an acute intuitive faculty. He writes: 'I conceive that most of the highest truths, are, to persons endowed by nature in certain ways which I think I could state, intuitive', and recognizes Carlyle as such a person. (Mill Letter to Thomas Carlyle, 5 July 1833 (78), CW XII: 163; Mill, Early Draft, ch. 5, $C W$ I: 182.) Significantly, he also characterizes Harriet Taylor in this manner: one with 'intuitive intelligence' and 'moral intuition' (Mill, Autobiography, ch. 6, CW I: 193, 197).

51 Mill, Coleridge, $C W \mathrm{X}$ : 121.

${ }^{52}$ Mill, Bain's Psychology, CW XI: 342. 
where the key differences between Mill's outlook and the intuitionist's lie.

Whether the intuitional fallacy really is a fallacy cannot be the subject of extended discussion here. I assume that it is at least plausible to think that Mill was on the right track in pursuing his empiricism this far. If all genuine knowledge of the external world comes from sensory perceptions of that world, then Mill is right to find any simple appeal to intuitions suspect. 'Of nature, or anything whatever external to ourselves, we know, according to [the empiricist] theory, nothing, except the facts which present themselves to our senses. ${ }^{, 53}$ But it is in simultaneously dismissing others' appeals to intuition while himself appealing to the mind's spontaneous tendencies to ground the normative that there is at least a prima facie tension in Mill's thought. Mill identifies the intuitional fallacy - to believe that the way the mind is composed can, on its own, act as a guide to how the rest of the world is. Yet if the trustworthiness of memory and induction, and the desirability of pleasure, are taken to be features of the world, he himself seems to commit the intuitional fallacy.

The intuitional fallacy tells us that we cannot know substantive facts about the world directly, by consulting our intuitions. The intuitional fallacy might be interpreted to imply that we can gain no knowledge at all by intuition, but it might equally be taken to imply that any valid knowledge we gain by reflection on primitive and spontaneous seemings is knowledge that pertains to something other than truths corresponding to substantive facts about the world. No substantive facts can be known other than via the mediation of sense experience, but it is open to Mill to claim that not all truths are truths about substantive facts about the world. The knowledge that we come to possess by reflecting on primitive and spontaneous seemings is not knowledge of substantive facts about the external world, that is to say, but a different sort of knowledge altogether.

This interpretation, then, separates Mill from the intuitionists by claiming that the knowledge that Mill believes is gained by 'intuition' is not knowledge of the world, but knowledge about reasons. We can know by reflection on our spontaneous dispositions that there is reason to believe this memory, that there is reason to trust inductive moves, or that there is reason to pursue pleasure, because these are not facts about the world, but normative truths. 'This apparent memory is trustworthy' is not a physical fact about and in the world; knowing that apparent memory is trustworthy is knowing that there is reason to trust and believe seeming memories. This is a normative truth. This, then, is 
the first key difference between the intuitionists and Mill. Whereas the intuitionists hold that substantive facts about the world - that every event has a cause, that the parallels postulate holds, that God exists can be accessed by intuition, Mill holds only that we can come to know about the norms of belief and action in this way. Of course, it would be fallacious to believe that we can come to know norms without the input of sense data if we thought that norms were natural objects inhabiting the world, but this itself would be a deeply strange belief.

Clearly, the interpretation will be untenable if it involves ascribing Mill a non-naturalist metaphysics. But as I hope is shown by the growing consensus that a belief in truths about a non-worldly normative domain is consistent with naturalism, it is not obvious that this interpretation would be in philosophic tension with Mill's naturalistic commitments. A belief that there are truths about reasons involves no metaphysical pledges: that there are truths about reasons tells us nothing about the metaphysics of those reasons. There need be no 'additions of being' posited for normative truths which do not correspond to natural facts, and a claim that we can come to know these truths by reflection on our primitive dispositions spontaneously to believe makes no commitments about coming to possess knowledge by any non-natural process. ${ }^{54}$

It might be objected that reasons are constrained by facts, which themselves must be known in order for us to have knowledge of norms. So, for instance, that there is reason to believe an apparent memory is constrained by the fact that apparent memories are accurate: were it the case that apparent memories were a bad guide to truth, there would be no reason to believe them. Therefore, the objection goes, we must know the constraining facts in order to know the norm: knowledge of the norm by intuition would involve knowing external facts. But Mill explicitly accepts that beliefs validly formed on the ground of primitive dispositions are subject to 'ulterior revision' in light of learning of

54 See D. Parfit, On What Matters, 2 vols. (Oxford, 2011), vol. 2, pp. 464-87; T. M. Scanlon, 'Metaphysical Objections', Being Realistic about Reasons (forthcoming); and J. Skorupski, The Domain of Reasons (Oxford, 2010), pp. 420-41. The views expressed by each author are different, but one commonality is a belief in irreducible norms that 'exist' in a different sense from 'exists' when it is applied within the domain of physical objects. Each takes his position to be compatible with a naturalistic ontology and epistemology. (While Parfit characterizes his position as 'non-naturalist', his non-naturalism is not a metaphysical view. He quotes Nagel approvingly: 'such normative claims "need not (and in my view should not) have any metaphysical content whatever"'. (Parfit, On What Matters, vol. 2, p. 486).) Compare also Dworkin's recent claim that 'if we want a genuine moral ontology or epistemology, we must construct it from within morality' and that the break from metaphysics must be a 'clean one' involving a conception of truth from 'within the realms of value itself' (R. Dworkin, Justice For Hedgehogs (Cambridge, MA, 2011), pp. 418, 38). 
the facts. ${ }^{55}$ This is the second key difference between Mill and the intuitionists with whom he disagrees. Though Mill claims that factual discovery need not, and cannot, be antecedent to taking our instinctual belief forming tendencies to be reason giving, he nevertheless remains humble about the pretensions of intuition. Reasons to believe that are suggested by our spontaneous dispositions are at all points defeasible.

[I]nduction by simple enumeration ... though a valid process, it is a fallible one, and fallible in very different degrees: if therefore we can substitute for the more fallible forms of the process, an operation grounded on the same process in a less fallible form, we shall have effected a very material improvement. And this is what scientific induction does. ${ }^{56}$

Mill makes this point clear with regard to induction, though it could equally have been made with regard to the norm of memory. Memory too is a valid but fallible process; we have pro tanto reason to trust memory on the basis of our spontaneous disposition to do so, though once this norm is recognized, it can be refined on the basis of empirical observations about the conditions in which apparent memory best tracks truth. Each, that is to say, can be 'set right when it is wrong'. ${ }^{57}$ There is more caution involved in Mill's use of these foundational dispositions than would be the case in an appeal to intuitions as axioms, which once established are never revisited. ${ }^{58}$

Can this also be said of the pleasure norm? In contrast to the theoretical cases, it is not obvious what it would mean for the pleasure norm to go wrong for us, and be in need of correction. While it is clear that our theoretical norms are hostage to results in the world - we know what it means for them to work well or fail at their predictive task - the practical case is more contentious. What would count as counterevidence - considerations that could compete with and correct the evidence we have for the pleasure norm - is difficult to specify. This is because we lack an independent idea of what it is that practical norms are supposed to do. But it seems that Mill does think that such counterevidence against the pleasure norm could in principle be given:

55 Mill, System, III.iv.2, CW VII: 318.

56 Mill, System, III.xxi.2, CW VIII: 568.

57 Mill, On Liberty, ch. 2, CW XVIII: 231.

58 I claim that this is a 'key difference', though of course it is in reality a key difference only between Mill and a particularly unsophisticated intuitionist. The thinkers he targets are not, in reality, committed to the claim that, once trusted, intuitions are philosophically unrevisable. Reid, for instance, writes that '[w] hen we come to be instructed by philosophers, we must bring the old light of common sense along with us, and by it judge of the new light which the philosopher communicates to us' (T. Reid, Inquiry and Essays, ed. R. E. Beanblossom and K. Lehrer (Indianapolis, 1983), p. 141, my emphasis). See J. Greco, 'Reid's Reply to the Skeptic', Cambridge Companion to Reid, ed. T. Cuneo and R. van Woudenberg (Cambridge, 2004), pp. 134-55, at 151, for discussion of Reid on revisability. 
this is why the 'proof' is provisional, and evidence of our disposition to desire pleasure must remain merely evidence. The pleasure norm cannot be established 'solely in the way of intuition', it must also be able to withhold challenges to 'determining the intellect' to withhold its assent from the principles. ${ }^{59}$ Whether evidence against the pleasure norm would take the form of establishing that the practical action prescribed is unconvincing or unmanageable, or merely showing that it does not help us to get by in the world, is not clear.

\section{CONCLUSION}

I have attempted in this article to show that Mill's relationship with intuitionism is more complex and ambivalent than is generally thought. Mill denies that many of the beliefs cited by intuitionists are in fact intuitions, and he is rightly sceptical of the claim that there can be any knowledge by intuition when it comes to substantive facts in the world. Nevertheless, he himself believes that certain genuine intuitions (or something very close) ground warranted normative beliefs. In these cases where we gain knowledge by intuition, however, I have suggested that Mill is not committed to believing that knowledge is gained of substantive facts about the world, for he need not regard normative propositions as worldly facts. And, I have noted, intuitions carry only pro tanto force: they are open to ongoing revision. This use of intuition does not violate his naturalism.

With all these caveats in place, there may be resistance to terming the primitive dispositions 'intuitions'. This is mainly a verbal dispute, and I do not intend this article to be terminologically legislative: insisting that Mill be called an 'intuitionist' would perhaps do more harm than good in placing him within the narrative of nineteenthcentury philosophy. Nevertheless, it is only in paying attention to his agreements as well as his disagreements with those who think that intuitions carry normative warrant that we will secure a full understanding of Mill's metaethical theory.

Clearly, much remains to be done in understanding Mill's metaethics. Only the broad outlines of his view have been sketched here. As noted above, we lack also a clear understanding of the process of revision and refinement of the results of examining our dispositions, especially in the practical case: theoretical norms are hostage to, and revisable in light of, their adequacy for forming correct beliefs, but it is not clear to what, if anything, our practical norms are hostage. We also lack an account of the durability of our spontaneous dispositions in untoward circumstances; we might feel uneasy that while our dispositions are 
malleable, our norms should not be. Additionally, there are also questions about the relation of our dispositions to Mill's multilayered axiology: how the process of coming to know what is desirable that has been outlined here relates to the selections of Mill's competent judges. These questions leave much work to be done. ${ }^{60}$

christopher.macleod@lancaster.ac.uk

${ }^{60}$ I owe thanks to James Harris, Dale Miller, John Skorupski and Robert Stern for useful comments on earlier versions of this article. 